\title{
Torque transducer with check standard combination
}

\author{
Tassanai Sanponpute and Chokchai Wattong \\ Torque laboratory, Mechanical Department, National Institute of Metrology (Thailand), Thailand
}

\begin{abstract}
The aim of this study was to fabricate a torque transducer that has two measurement signals in order to simultaneously measure torque value and check its stability. The transducer has two sensing bodies aligned in the same measurement axis. The first sensing body was designed to be a measurement signal and the second sensing body was designed to be a check signal. The capacity of the check signal was designed at least two times larger than that of the measurement signal. Transducers with various capacity ratios of check signal and measurement signal with ratios $2: 1,3: 1$ and $4: 1$ were fabricated. To confirm the assumption that the fabricated transducers are able to check stability by themselves, they were overloaded from $100 \%$ to $800 \%$ of their capacity. The experimental results showed that the function ratios of the check signal and measurement signal corresponds with the stability measured by a torque standard machine. Thus it can be used to predict stability. Stabilities of the check and zero signals are used to find the appropriate capacity ratio. It was found that the stability of check and zero signals showed drift caused by overload. Therefore, the capacity ratio should be designed at least 3:1 for transducers made of steel and 2:1 for transducers made of aluminum. A prototype of a torque transfer wrench was also made according to the concept of the torque transducer with check standard combination. Experimental results corresponds with results of the torque transducer. It could also check the stability itself.
\end{abstract}

\section{Section: RESEARCH PAPER}

Keywords: torque transducer; check standard; Intermediate check

Citation: Tassanai Sanponpute and Chokchai Wattong, Torque transducer with check standard combination, Acta IMEKO, vol. 6, no. 2, article 10, July 2017, identifier: IMEKO-ACTA-06 (2017)-02-10

Section Editor: Min-Seok Kim, Research Institute of Standards and Science, Korea

Received June 30, 2016; In final form June 1, 2017; Published July 2017

Copyright: @ 2017 IMEKO. This is an open-access article distributed under the terms of the Creative Commons Attribution 3.0 License, which permits unrestricted use, distribution, and reproduction in any medium, provided the original author and source are credited

Funding: This work was supported by the National Institute of Metrology (Thailand)

Corresponding author: Tassanai Sanponpute, e-mail: tassanai@nimt.or.th

\section{INTRODUCTION}

The calibration status of a torque transducer used in any permanent laboratory or an on-site area shall be periodically confirmed by means of intermediate checks, which is one of the ISO/IEC 17025:2005 requirements [1]. An intermediate check activity cannot be replaced by calibration. It is an extra activity that should be done during a calibration interval and after using the torque transducer in an uncontrolled area. Usually the intermediate check will have a procedure to compare the measurement results with the check standard, which can be another torque transducer. The frequency of the intermediate check basically depends on the number of uses and a torque transducer with high stability must be used as a check standard. The problem is that an intermediate check is a time-consuming process. We intend to reduce the working time for the intermediate check by introducing a new transducer design. Torque transducers giving two signals at the same time were designed in order to confirm the calibration status during the measurements. We studied this concept by fabricating the prototype $50 \mathrm{~N} \cdot \mathrm{m}$ torque transducer with a check standard combination [2]. During the measurements, an intermediate check was also carried out. When torque is applied the transducers, two measurement and check signals are produced at the same time. Thus, the comparison between measurement and check signals could be done as a basic principle of the intermediate check. A prototype is shown in Figure 1.

The ratio of check and measurement signals was calculated using (1), hereafter named the function ratio. It was used to predict the stability or sensitivity change of the transducer.

$$
\text { Function ratio }=\frac{\text { Check signal }}{\text { Measurement signal }} \text {. }
$$

The results expressed that the trend of the function ratio was consistent with the trend of stability measured by using a torque standard machine (TSM). Thus, the fabricated transducers can simultaneously measure torque and carry out an 


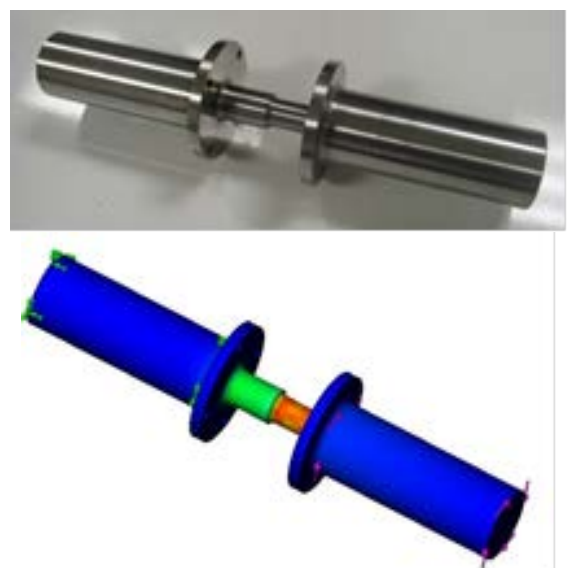

Figure 1. Prototype of the $50 \mathrm{~N} \cdot \mathrm{m}$ torque transducer with check standard combination.

intermediate check by itself. However, this previous research just focused on the preliminary feasibility study. There was no information of an appropriate ratio of check and measurement capacities (hereafter named capacity ratio), zero signal drift and material. This research aims to find out the appropriate capacity ratio, zero signal drift and material to gain a more precise prediction of the measurement stability for practical uses.

\section{EXPERIMENTAL PLAN}

This research started from the design and structure of torque transducers with a capacity ratio between 2:1, 3:1 and 4:1 and made of two different materials: steel and aluminium. Two signals, a check and a measurement signal of the fabricated transducers were measured by torque capacity with the TSM. At the time of the measurement, the zero signal was also recorded. Then the boundary line of stability was evaluated based on three times the standard deviation. Additionally, the function ratio was calculated.

To prove how precise the function ratio can predict the stability change of the transducer, it is needed to demonstrate an influence quantity which causes a stability change of the transducer. Overload is one of the obvious factors and can quickly create a disturbance. Moreover, it is clearly observable. In this study an experimental plan with overload test is presented. Previous research [2] showed that a $200 \%$ overload test cannot cause a significant change in stability of the fabricated transducer. Therefore, this continuing study aims to extend the overload test up to $800 \%$ where a stability change and zero signal drift can be clearly observed. Other influence quantities that affect the stability of the torque transducer were investigated in this research. The overload test started from 100 $\%$ to $800 \%$ of capacity and after each overload, the stability of the transducer, the zero signal drift and the function ratio were evaluated.
Finally, the changed torque sensitivity caused by overload was compared with the function ratio to evaluate the effectiveness of the stability prediction. Additionally, an appropriate capacity ratio was evaluated based on the check signal and zero signal drift.

\section{DESIGN AND FABRICATION}

\subsection{Sensing body design}

The torque transducer with check standard combination was designed to have two sensing bodies aligned in the same measurement axis so that they undergo the same amount of torque. As per conceptual design, the sensing body of the check signal must be stronger than the body of the measurement signal and consequently the capacity of the check signal will be larger than that of the measurement signal. During the measurement, an intermediate check was also carried out. The conceptual operation is illustrated in Figure 2.

The sensing body was designed as a cylindrical shape. Details of the design including verification with finite element models are given in [2]. This research aimed to discover the effect of the material used to make the sensing body. Tool steel grade DC53 [3] and aluminium grade AI 6061-T6 [4] were selected for the fabrication of the transducers. All four transducers were made with different capacity ratios as described in Table 1.

\subsection{Full bridge strain gauge circuit}

A biaxial strain gauge model FCT-2-350-C2-11 manufactured by TML [5] was used in a full bridge strain gauge circuit. The technical specifications were as follows: $2 \mathrm{~mm}$ gauge length, $2.07 \pm 1 \%$ gauge factor and $350 \Omega$ resistance. So, the full bridge circuit was made with nominal sensitivity 2.07 $\mathrm{mV} / \mathrm{V}$ at $0.001 \mathrm{~m} / \mathrm{m}$ strain rate. The circuit is illustrated in Figure 3. The strain gauges were mounted at positions $0^{\circ}$ and $180^{\circ}$ along the cylindrical sensing body. However, no temperature compensation and zero balance were included in this circuit [6].

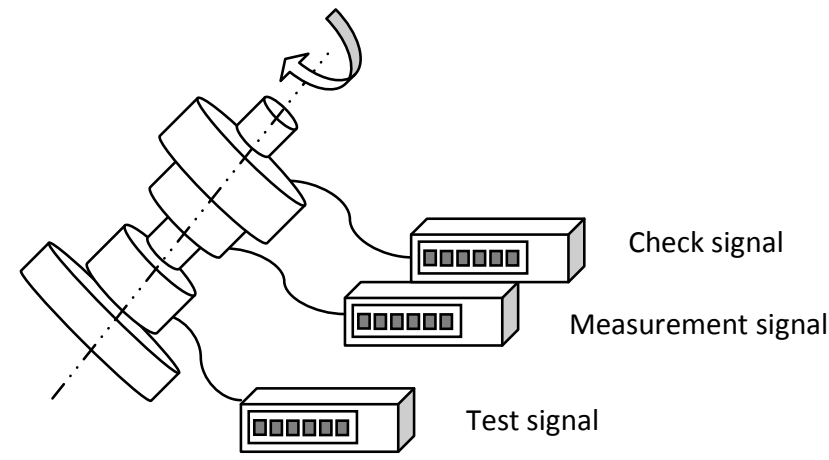

Figure 2. The conceptual operation of the transducer with check standard combination.

Table 1. Details of the designed transducer.

\begin{tabular}{|c|c|c|c|c|}
\hline Model & Capacity Ratio & Measurement capacity $(\mathrm{N} \cdot \mathrm{m})$ & Check capacity $(\mathrm{N} \cdot \mathrm{m})$ & material \\
\hline $012: 150 \mathrm{~S}$ & $2: 1$ & 50 & 100 & Tool steel \\
\hline $023: 1305$ & $3: 1$ & 30 & 100 & Tool steel \\
\hline 03 4:1 50A & $4: 1$ & 50 & 200 & Aluminum \\
\hline $042: 1100 \mathrm{~A}$ & $2: 1$ & 100 & 200 & Aluminum \\
\hline
\end{tabular}




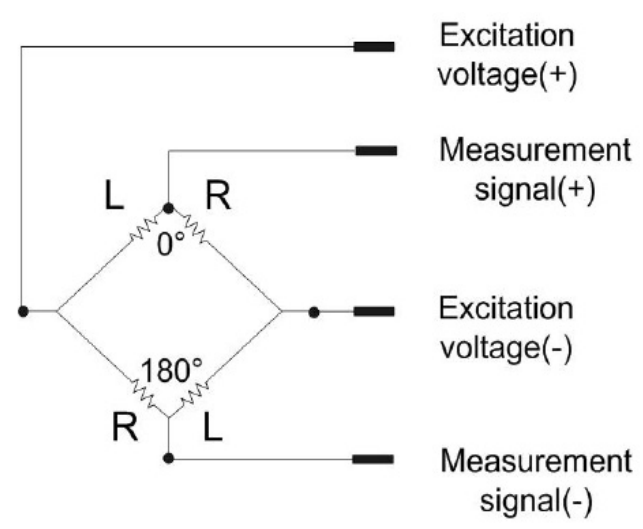

Figure 3. Full bridge strain gauge circuit used in the transducers.

The four completed transducers are shown in Figure 4.

\section{RESULTS AND DISCUSSION}

\subsection{Stability at normal condition}

The stability of the transducers was monitored over a period of 60 days. The stability of the measurement signal, the check signal and zero signals are shown in terms of variations from the normal condition. All transducer gave similar results. There were just slight differences in the mean values and variations. The stability trend of transducer model 04 2:1 100A is shown in Figure 5 as an example.

All stability data were evaluated based on a boundary line or verification criteria of the intermediate check. When the measurement result deviated from the mean value over the boundary line, it assumed this was affected significantly by external influence factors. The mean values and boundary line are shown in Table 2.

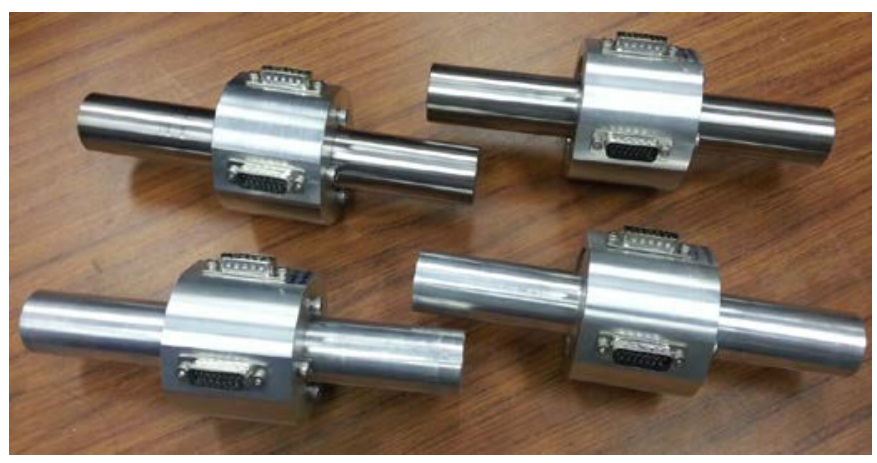

Figure 4. Fabricated torque transducer with check standard combination.
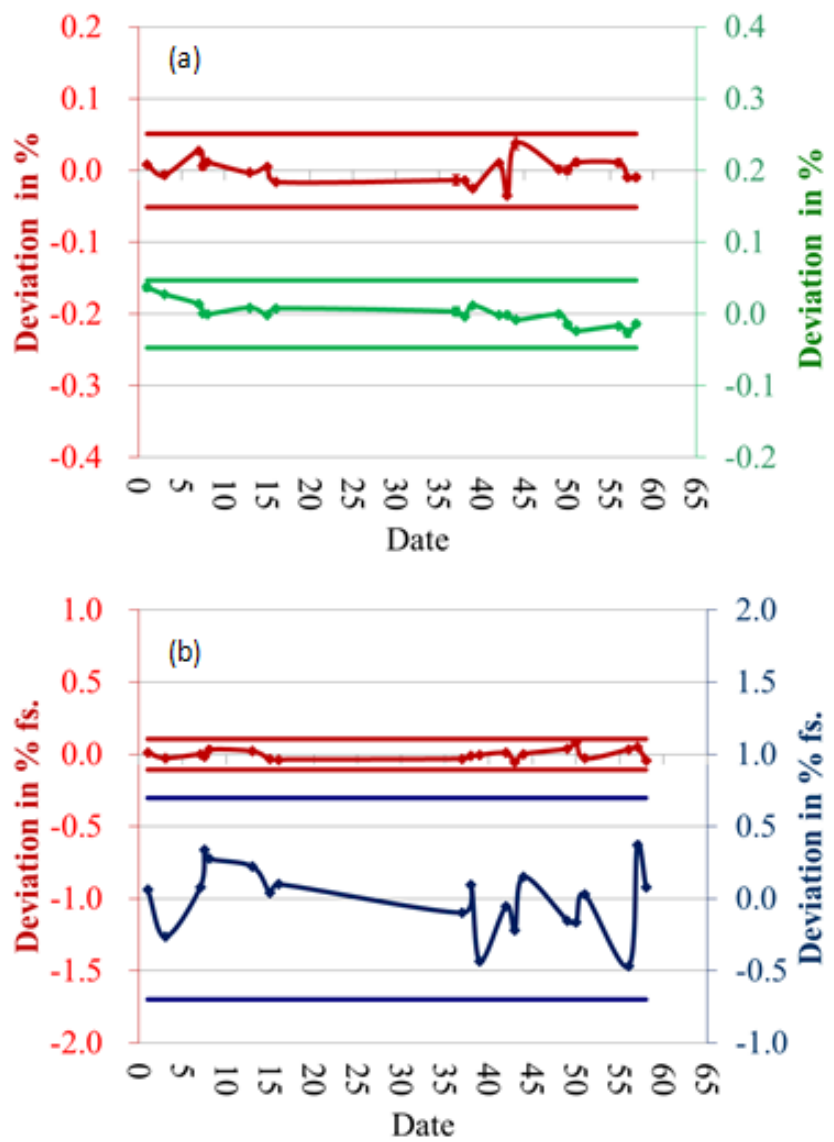

Figure 5. Trend of stability of transducer model 04 2:1 100A, (a) stability of the measurement signal (red line) and function ratio (green line), (b) zero signal drift of the measurement signal (red line) and check signal (blue line).

\subsection{Stability change vs. Function ratio}

The applied overload tests from $100 \%$ to $800 \%$ capacity impacted directly upon the measurement signal. The sensitivity of the transducer can be stable and the results of both measurement signals and function ratios are within the boundary line (red and green line, respectively) unless it experienced large amounts of overload. When the transducer received a torque over the yield point (approximately $300 \%$ for aluminium and $700 \%$ for heat treated steel), the sensitivity changed correspondingly to the applied overload. The results of the overload test, the measurement signal and the function ratio changes of four transducers are illustrated in Figure 6.

Figure $6 \mathrm{a}$ and $6 \mathrm{~b}$ illustrate that the transducers made of tool steel, model 01 2:1 50S and model 02 3:1 30S, can withstand an

Table 2. Evaluation results of long-term stability of transducers.

\begin{tabular}{|c|c|c|c|c|c|c|c|c|c|c|}
\hline \multirow{3}{*}{ Model } & \multicolumn{6}{|c|}{ Stability at capacity } & \multicolumn{4}{|c|}{ Zero drift } \\
\hline & \multicolumn{2}{|c|}{ Measurement signal } & \multicolumn{2}{|c|}{ Check signal } & \multicolumn{2}{|c|}{ Function ratio } & \multicolumn{2}{|c|}{ Measurement signal } & \multicolumn{2}{|c|}{ Check signal } \\
\hline & $\begin{array}{l}\text { mean } \\
\text { value } \\
(\mathrm{mV} / \mathrm{V})\end{array}$ & $\begin{array}{l}\text { boundary } \\
\text { line } \\
\text { +/- \%rdg }\end{array}$ & $\begin{array}{l}\text { mean } \\
\text { value } \\
(\mathrm{mV} / \mathrm{V})\end{array}$ & $\begin{array}{l}\text { boundary } \\
\text { Line } \\
\text { +/- \%rdg }\end{array}$ & $\begin{array}{c}\text { mean } \\
\text { value } \\
\text { per unit }\end{array}$ & $\begin{array}{l}\text { boundary } \\
\text { line } \\
\text { +/- \%rdg }\end{array}$ & $\begin{array}{l}\text { mean } \\
\text { value } \\
(\mathrm{mV} / \mathrm{V})\end{array}$ & $\begin{array}{c}\text { boundary } \\
\text { line } \\
\text { +/- \%fs }\end{array}$ & $\begin{array}{l}\text { mean } \\
\text { value } \\
(\mathrm{mV} / \mathrm{V})\end{array}$ & $\begin{array}{c}\text { boundary } \\
\text { line } \\
\text { +/- \%fs }\end{array}$ \\
\hline $012: 150 S$ & 2.02619 & 0.03 & 1.00476 & 0.03 & 2.01659 & 0.02 & -0.24995 & 0.22 & -0.09608 & 0.24 \\
\hline $023: 1305$ & 2.04259 & 0.10 & 0.60391 & 0.05 & 3.38228 & 0.07 & 0.45035 & 0.87 & 0.07526 & 2.8 \\
\hline $034: 150 A$ & 2.09517 & 0.06 & 0.47410 & 0.07 & 4.41941 & 0.03 & 0.59860 & 0.15 & 0.62303 & 1.7 \\
\hline $042: 1$ 100A & 2.10303 & 0.05 & 0.95691 & 0.07 & 2.19774 & 0.05 & 0.57976 & 0.11 & 0.20061 & 0.70 \\
\hline
\end{tabular}



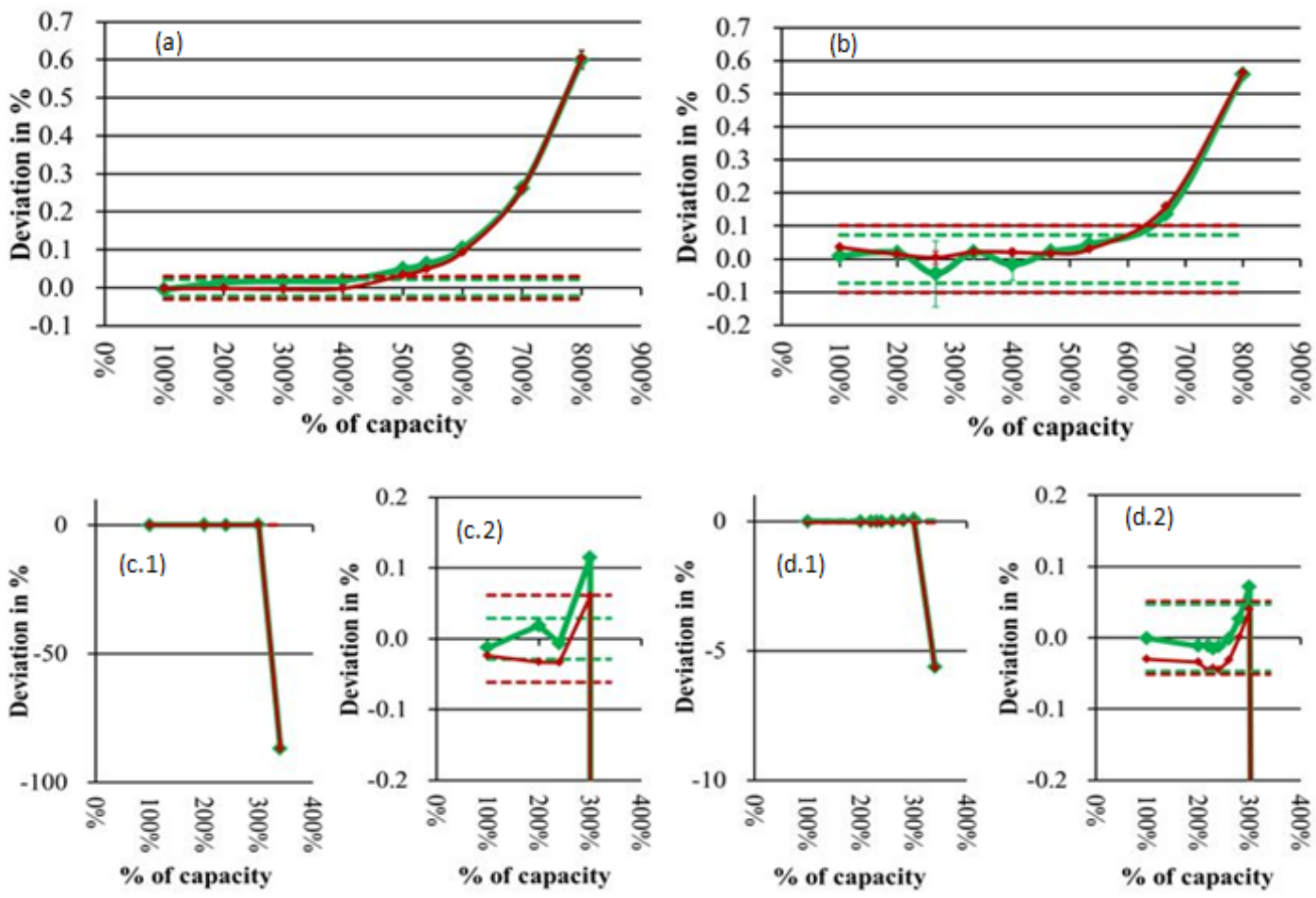

Figure 6. The stability change after an overload of $100 \%$ to $800 \%$ of the measurement signal (red line) compared with the function ratio (green line) for transducer model (a) 01 2:1 50S, b) 02 3:1 30S, c) 03 4:1 50A and d) 04 2:1 100A.

overload up to $500 \%$ of the capacity. Within this overload range the variation of the sensitivity was steady within the boundary line. Afterwards the sensitivity increased up to $0.6 \%$ at $800 \%$ applied overload.

On the other hand, the transducers made of aluminium, model 03 4:1 50A and model 04 2:1 100A, as shown in Figure $6 \mathrm{c}$ and $6 \mathrm{~d}$, can withstand an overload up to $300 \%$ of the capacity. The sensitivity variations were still within the boundary line as long as they received an overload not more than $300 \%$ of the capacity. Then the sensitivity abruptly changed after receiving an overload at $340 \%$ and could not be tested anymore because the sensing body was damaged or the material has reached its ultimate strength. Therefore, it is like a common torque transducer that cannot be used in case of overload up to the yield or failure point even when it is in the reference type of the torque calibration machine or the deadweight type torque standard machine.

Considering the trend of the function ratio and stability, it was found that the trend of the function ratio corresponds to the sensitivity change that was obtained by measuring with the TSM. All transducers showed the same agreement even in the case of broken transducers. Thus, the results confirmed that the monitoring function ratio was able to predict the stability of the transducers designed and fabricated in this research. These transducers can be used when an ordinary intermediate check process cannot be performed. However, the correlations may not be better than $0.05 \%$ as shown in Figures 6c.2 and 6d.2.

\subsection{Stability of the check signal}

Even though the test results showed that the function ratio can predict the stability of the transducer, the stability of the check signal is still one of the dominant factors that affect the precision of prediction. The stability of the check signal should be within the boundary line during the overload test. The trend of stability of the check signal after receiving overloads of 100 $\%$ up to $800 \%$ of the capacity is illustrated in Figure 7.

Figure 7 demonstrates that the check signal obtained a good stability. The sensitivity of the check signal is distributed within the boundary line. It proved that the overload test does not affect the sensitivity of the check signal. The capacity ratios of the fabricated transducers were 2:1, 3:1 and 4:1 as detailed in Table 1. Therefore, the design of the lowest capacity ratio, 2:1, is effective to ensure the stability at the capacity.

\subsection{Zero signal drift}

As per conceptual design, the sensing body of the check signal should be stronger than that of the measurement signal so that the check signal would be more reliable than the measurement signal. Moreover, the capacity ratio of the check capacity and measurement capacity were used to define how much stronger the check signal was. Although the test result showed that the check signals of four transducers obtained good stability as mentioned above, the zero signal drift was one source affecting the precision of the stability prediction. Thus not only the stability of the check signal but also its zero signal drift contributes to the appropriate capacity ratio. Test results of the zero signal drift of check and measurement signals are shown in Figure 8.

Also, the zero signal of the check signal of the steel transducers slightly changed, because the sensing bodies were designed to have a capacity larger than that of the measurement. However, transducer capacity 2:1, shown in Figure $8 \mathrm{a}$, obtained a change rate more than the capacity ratio 3:1 shown in Figure 8b. Capacity ratio 3:1 could maintain a zero signal of the check signal within the boundary line, whereas capacity ratio 2:1 could not. Consequently, it can be said that transducers made of steel should be designed with a capacity ratio of at least 3:1. 

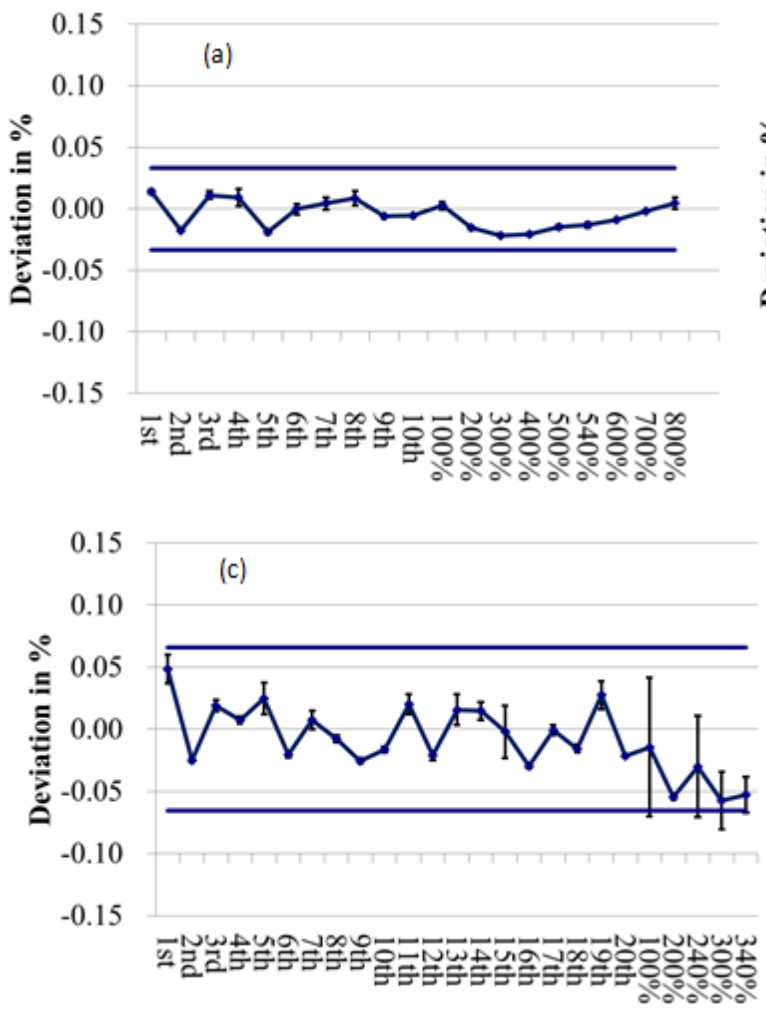
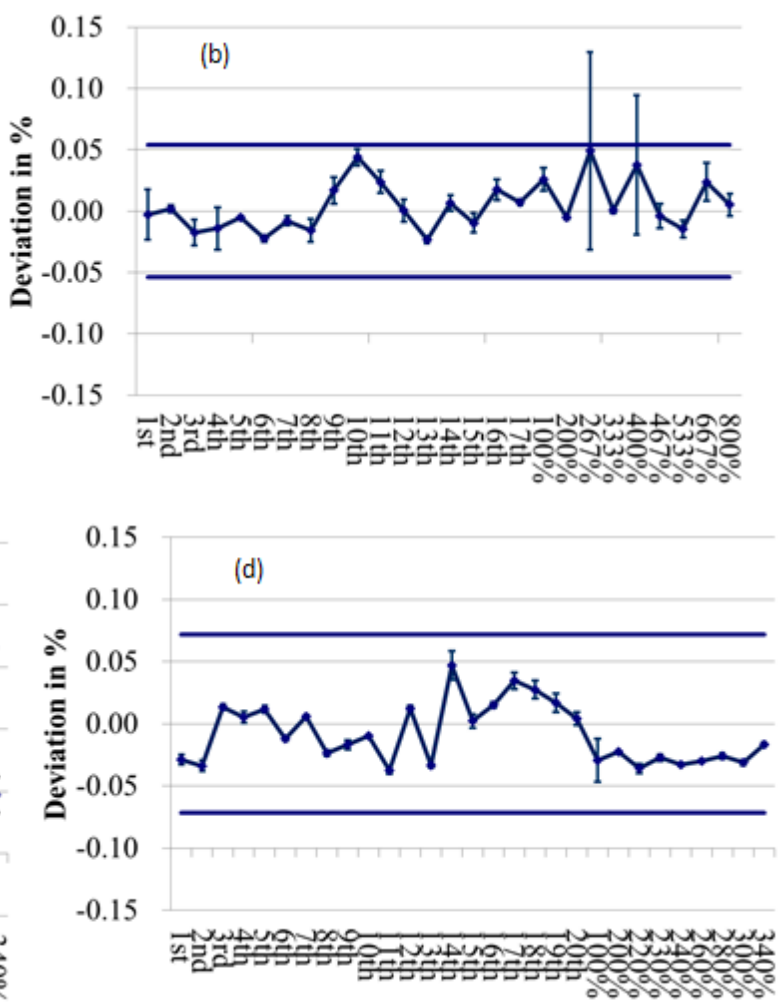

Figure 7. Stability of the check signal after receiving overloads from $100 \%$ to $800 \%$ of the capacity for transducer models (a) $012: 150 S$, (b) $023: 130 S$, (c) 03 4:1 50A and (d) 04 2:1 100A.

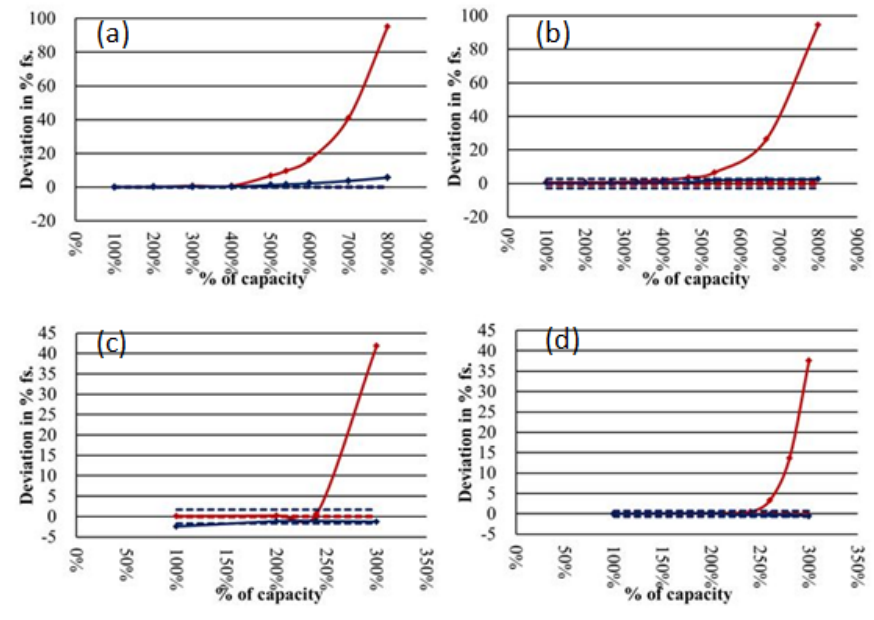

Figure 8. Zero signal drift of the measurement signal (red line) compared with the check signal (blue line) for transducer models (a) 01 2:1 50S, (b) 02 3:1 30S, (c) 03 4:1 50A and (d) 04 2:1 100A.

The zero signal of the check signal of the aluminium transducer was quite steady. Zero signals of the capacity ratio 4:1 and 2:1 shown in Figures 8c and 8d, respectively, were within the boundary line over the overload $40 \%$ of capacity. Therefore, the aluminium transducer can be designed with a capacity ratio just $2: 1$, which is sufficient.

\section{THE PROTOTYPE OF TORQUE TRANSFER WRENCH WITH CHECK STANDARD COMBINATION}

After the successful experiment with the torque transducer, authors were interested to apply this concept to the torque transfer wrench. Hence, a prototype of the torque transfer wrench with check standard combination was invented. Its sensing body was of the bending type, made of aluminium, capacity $50 \mathrm{~N} \cdot \mathrm{m}$ and a capacity ratio at $2: 1$. The prototype is illustrated in Figure 9.

The investigations followed the experimental plan for torque transducers as stated above. The torque standard machine was still needed for carrying out the stability tests as shown in Figure 10.

The results showed that the stability at normal condition was similar to the transducer in the previously mentioned experiment. They amount $\pm 0.08 \%$ for the stability of the measurement signal and the check signal. The calculated function ratio was 2.0034:1 with a boundary within $\pm 0.03 \%$. Then overload tests were done in order to confirm the function ratio capability to predict the stability of the torque transfer wrench compared with the stability obtained by measurements with the TSM. Test results showed a good consistency between

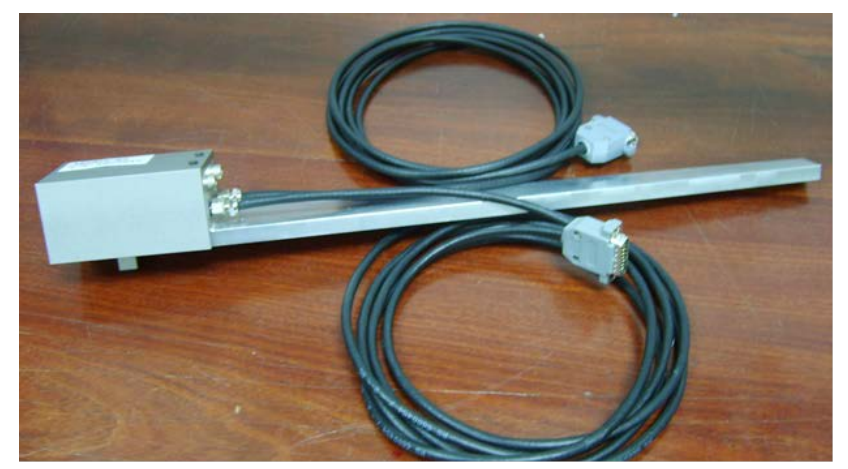

Figure 9. The prototype of the torque transfer wrench with check standard combination. 


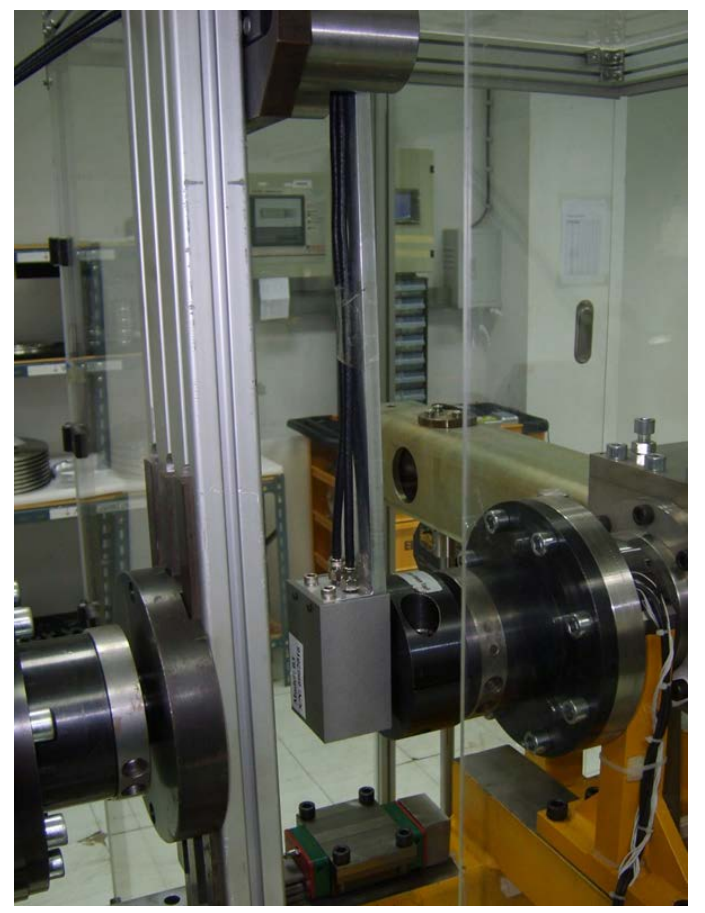

Figure 10. The experimental setup for stability of the torque transfer.

each other as illustrated in Figure 11. However, the sensing body of the torque transducer and torque transfer wrench can be damaged at high torques. Based on the experiments, the torque transducer damaged at $300 \%$ of the torque capacity while the torque transfer wrench damaged at $450 \%$ of the torque capacity.
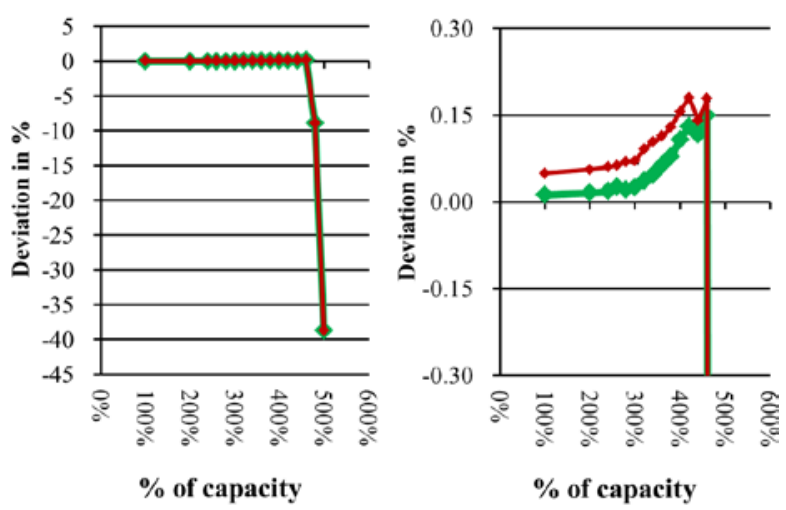

Figure 11. The prototype of torque transfer wrench with check standard combination.

\section{CONCLUSION}

Transducers made of steel were able to bear overload tests up to $500 \%$ of their capacity. The sensitivity and zero signals could be changed according to the amount of overload applied. Transducers made of aluminium were able to bear overload tests just at $300 \%$ of the capacity and could be damaged when the overload exceeded $300 \%$.

The function ratio can be used to predict the stability of the fabricated torque transducer. Consequently, the torque transducer with check standard combination can perform a measurement and in the meantime carrying an intermediate check itself. A capacity ratio of at least 3:1 for the steel transducer and 2:1 for the aluminium transducer should be considered.

The prototype of the torque transfer wrench with check standard combination was additionally made for investigations. The study results obviously showed consistency with the torque transducer that was studied previously. However, the breaking points of the torque transducer and torque transfer wrench were different. They could be caused by the structure and type of sensing bodies. In order to better understand their characteristics, further experiments will be conducted.

\section{ACKNOWLEDGEMENT}

Authors would like to express our sincere thanks to Miss Apichaya Meesaplak and Dr. Kittisun Mongkolsuttirat for proofreading.

\section{REFERENCES}

[1] ISO/IEC 17025:2005, General requirements for the competence of testing and calibration laboratories, 2005.

[2] Tassanai Sanponpute, Chokchai Wattong, "50 N m Torque Transducer with Check Standard Combination", Proc. of 18th IE NETWORK Conference, Aug. 6-7, 2015, Bangkok, Thailand. pp.720-725.

[3] DC53 high hardness \& Toughness new general-purpose cold die steel (homepage on the Internet). (Cited 2017 June 15). Available from: http://www.daido.co.jp/en/products/tool/pdf/dc53.pdf

[4] Aluminium 6061-T6; 6061-T651 (homepage on the Internet). (Cited 2017 June 15).

Available from: http://www.matweb.com/search/datasheet print.aspx?matguid $=1 \mathrm{~b} 8 \mathrm{c} 06 \mathrm{~d} 0 \mathrm{ca} 7 \mathrm{c} 456694 \mathrm{c} 7777 \mathrm{~d} 9 \mathrm{e} 10 \mathrm{be} 5 \mathrm{~b}$

[5] TML Strain Gauge Performance Characteristics (homepage on the Internet). (Cited 2017 June15).

Available from:

http://www.straingage.com/2011/pages/TMLStrainGaugePerfo rmanceCharacteristics.pdf

[6] Omega Engineering, The pressure, strain and force handbook Vol.29 (Strain gauges E-5, E-6), 1995. 